\title{
MAKER: Generation of Electricity from Bacteria Present in Waste Water
}

\section{Dr. Hugh Jack P.E., Western Carolina University}

Dr. Jack is not the author. The abstract has been submitted on behalf of Parimala Nair - VIT University, Vellore, India. 


\title{
Generation of Electricity from Bacteria Present in Waste Water
}

\section{Author}

Parimala Nair, VIT University, Vellore, India

\begin{abstract}
In today's world, the energy demand is skyrocketing and conventional, non-renewable resources are being consumed at a very high rate. Fossil fuels like coal and petroleum are predicted to exhaust in a few years from now. Apart from that burning fossil fuels have disadvantages such as they influence climatic change and global warming and they cause serious health issues (like respiratory illness, heart disease, and asthma) when exposed frequently. Most of the energy requirements of the world are met by non-renewable resources. The world is becoming aware of the situation and opting for sustainable energy options. Hence sustainable options are the need of the hour.
\end{abstract}

The idea of the generation of electricity from microbes is what I call the TAP technology. Waste water is a repository of microorganisms. We could use the internal machinery of these organisms to produce electricity. The metabolism of the microorganisms involves breaking down of complex organic matter such as sugars to produce electrons, as shown below. $\mathrm{C} 12 \mathrm{H} 22 \mathrm{O} 11+13 \mathrm{H} 2 \mathrm{O} \rightarrow 12 \mathrm{CO} 2+48 \mathrm{H}++48 \mathrm{e}-$ The electrons produced help conduct electricity with an appropriate setup. A TAP plant has two compartments. One compartment holds the wastewater and the other contains copper sulfate solution (or any salt solution). The wastewater compartment is the anode since it is where the oxidation takes place and electrons are transferred to the carbon electrode. The compartment containing copper sulfate solution is the cathode. A copper electrode installed in this compartment. In order to complete the circuit, a salt bridge is required. However, in large-scale implementation of TAP technology, a semi-permeable membrane can be used. A TAP plant set up is similar to a galvanic cell. The conduction of electricity is due to potential difference created across the electrodes dipped in each of the compartments in the TAP plant. TAP technology not only produces electricity but also cleans the wastewater. In the process of electricity generation; the microorganisms die resulting in the purification of water. TAP technology coupled with wastewater treatment plants can 
prove to be highly efficient. TAP is a great solution to the energy problem the world faces 